\title{
Stage pTO Prostate Cancer: A Single-Center Study and Literature Review
}

\author{
(1) Kaan Karamık1, (1) Mahmut Taha Ölçücü2, (1) Ekrem İslamoğlu22, (1) Kayhan Yılmaz², (1) Okan Alkış33, (1) Şenay Yıldırım4 (1) Mutlu Ateş2 \\ ${ }^{1}$ Korkuteli State Hospital, Clinic of Urology, Antalya, Turkiye \\ 2University of Health Sciences Turkiye, Antalya Training and Research Hospital, Clinic of Urology, Antalya, Turkiye \\ ${ }^{3}$ Kütahya Health Sciences University, Evliya Çelebi Training and Research Hospital, Clinic of Urology, Kütahya, Turkiye \\ ${ }^{4}$ University of Health Sciences, Antalya Training and Research Hospital, Clinic of Pathology, Antalya, Turkey
}

\section{What's known on the subject? and What does the study add?}

Stage pT0 prostate cancer (PCa) after radical prostatectomy is a rare phenomenon with unclear significance. Patients with a Gleason score of 6 and tumors in a single core and length of $<2 \mathrm{~mm}$ in the biopsy have a higher risk of stage pT0 PCa.

\section{Abstract}

Objective: To report our experience with biopsy positive T0 prostate cancer (PCa) and perform a literature review to determine the frequency, clinical outcomes, and predictors of pT0 PCa after radical prostatectomy (RP).

Materials and Methods: The records of 497 patients who underwent robot-assisted RP at our institution between 2015 and 2020 were retrospectively reviewed. No patients were diagnosed after the transurethral prostate resection or received preoperative hormone therapy. Clinicopathological features including age, prostate-specific antigen (PSA), body mass index, digital rectal examination, biopsy results, clinical T stage, D'Amico risk, prostate weight, prostatectomy pathology, and follow-up data were analyzed.

Results: Overall, 3 patients were classified as PT0 on pathologic examination of the RP. The biopsy re-evaluation revealed that 1 patient did not have PCa. Subsequently, the entire RP specimens were re-analyzed, wherein 2 cases were signed out with no identified carcinoma. The incidence of the pTO PCa was $0.4 \%$ in our series. The median age of patients was 64 years. The median PSA was $14.27 \mathrm{ng} / \mathrm{mL}$. Biopsy Gleason score of 2 patients was reported as $3+3$. All patients had a tumor in only one core and all were in clinical stage T1c. No biochemical recurrence was found in a mean 21-month follow-up. Eleven studies were identified involving 26,228 patients, wherein $122(0.46 \%)$ were reported with pT0 cases. Most patients with stage pT0 have been reported to have a Gleason score of $<7$, only one positive core biopsy, and a tumor length of $<2 \mathrm{~mm}$.

Conclusion: Patients with a Gleason score of 6 and tumors in a single core and length of $<2 \mathrm{~mm}$ in the biopsy should be informed about the risk of stage pT0.

Keywords: Prostate cancer, residual cancer, surgical pathology, prostatectomy

\section{Introduction}

Prostate cancer ( $\mathrm{PCa}$ ) is the most commonly diagnosed cancer in men and is also second-ranked cancer that results in death in the United States (1). Currently, radical prostatectomy (RP) remains the gold standard surgical treatment for localized PCa. Widespread use of prostate-specific antigen (PSA) screening has resulted in an increased number of patients diagnosed with small-volume and low-grade tumors. Correspondingly, the volume of residual cancer in RP specimens has decreased
(2). In some cases, no demonstrable cancer is identified in the entire RP specimen despite prior positive biopsy. The inapperent cancer after the RP has been referred to as the 'vanishing cancer phenomenon' that was first described by Goldstein et al. in 1995 (3). The vanishing cancer phenomenon is defined as stage pTO according to the Tumor, Node, and Metastasis classification. The rate of pT0 cystectomy specimens has ranged between $5.1 \%$ and $20.1 \%$ (4). However, the unusual event occurs in $<1 \%$ of all RPs (5). Patients who have had neoadjuvant hormonal therapy or prior transurethral resection of the prostate (TURP) experience

Correspondence: Mahmut Taha Ölçücü MD, University of Health Sciences Turkiye, Antalya Training and Research Hospital, Clinic of Urology, Antalya, Turkiye Phone: +90 5335122284 E-mail: matah_ol@hotmail.com ORCID-ID: orcid.org/0000-0002-4721-2807

Received: 11.03 .2021 Accepted: 01.08 .2021

Cite this article as: Karamık K, Ölçücü MT, İslamoğlu E, Yılmaz K, Alkış O, Yıldırım Ş, Ateş M. Stage pTo Prostate Cancer: A Single-Center Study and Literature Review. J Urol Surg 2021;8(4):255-260.

๑Copyright 2021 by the Association of Urological Surgery / Journal of Urological Surgery published by Galenos Publishing House. 
more commonly pT0 disease after the $\operatorname{RP}(2,6)$. The finding of pT0 disease following the RP is a challenging situation with unclear significance.

This study aimed to report the results of pT0 tumors after the $\mathrm{RP}$ at our institution. Additionally, the literature review was performed to determine the incidence, clinicopathological characteristics, and follow-up data of no residual cancer following RP.

\section{Materials and Methods}

\section{Study Population}

After the local institutional review board approval (approval number: 2021-007), we retrospectively identified the prospectively maintained robotic surgery database records of 497 patients who underwent robot-assisted RP (RARP) between March 2015 and June 2020 in our institution. The study was approved by Antalya Training and Research Hospital Ethics Committee (approval number: 2021-007). Patients who received hormonal therapy before the surgery $(n=2)$ or who were diagnosed with PCa after TURP $(n=4)$ were excluded from the study.

\section{Acquisition and Definition of Data}

For each case, patient age, PSA level, body mass index, digital rectal examination (DRE) finding, prostate biopsy results (number of biopsy core, number of positive core, length of positive core, percentage of cancer, and Gleason score), clinical T-stage, D'Amico risk group, prostate weight, prostatectomy pathology results (pathological N stage, RP diagnosis), last visit PSA level, and follow-up time were recorded.

PubMed, Web of Science, Scopus/Science Direct, Wiley Online, and Google Scholar databases were scanned for the literature review. Scanning the literature was performed using the keywords: vanishing cancer, $\mathrm{pTO}, \mathrm{PCa}$, and no residual tumor.

\section{Surgical Technique and Follow-up}

Radionuclide bone scans were performed in symptomatic patients and patients with PSA levels of $>10 \mathrm{ng} / \mathrm{mL}$. The multiparametric magnetic resonance imaging was performed in all patients. All patients had a clinically localized PCa at the time of surgery. All patients underwent RARP. Our surgical technique of RARP has been described (7). Bilateral pelvic lymphadenectomy was performed in all high-risk and selected intermediate-risk patients according to the Briganti nomogram. Patients were followed up postoperatively with PSA every 3 months for the first year, every 6 months for the second year, and annually thereafter. The biochemical recurrence (BCR) was defined by two consecutive PSA levels of $\geq 0.2 \mathrm{ng} / \mathrm{mL}$.

\section{Pathological Examination}

All RP specimens were sampled and examined using a standard protocol $(8,9)$. Prostate needle biopsies were re-evaluated when no residual tumor was found following the histological review. After excluding false-positive prostate needle biopsy, entire RP specimens are re-analyzed. The slides of the surgical specimens were reviewed for residual cancer by a dedicated pathologist. The remaining prostate tissue was processed in toto if the RP specimen was not embedded. Three additional deeper sections of the RP tissue block corresponding to the tumor area of the biopsy were re-cut. After block-flipping, additional deeper sections were prepared. Immunohistochemical analysis was done if a lesion suspicious for cancer was present. The RP specimen was signed out as showing no residual cancer if cancer is not found after all of these steps. Cases were included in this study after confirmation of no residual tumor (pT0).

\section{Statistical Analysis}

Our study performed no statistical analysis due to insufficient data groups requiring statistical analysis. The data of patients were expressed as mean, minimum-maximum, and percentage.

\section{Results}

The clinical data of all cases with a postoperative pT0 stage were extracted from the database, wherein 3 cases were identified. All prostate biopsies corresponding to the pT0 tumors were reviewed by a second pathologist, and PCa diagnosis was not confirmed in 1 patient. After excluding this patient, RP specimens of 2 patients were re-analyzed. No residual tumor was found. The patient characteristics are listed in Table 1. The median age of patients was 64 years (range, 62-66). No abnormal findings were detected in the DRE of these patients. The median PSA was $14.27 \mathrm{ng} / \mathrm{mL}$ (range, 3.93-24.62). In all cases, PCa was diagnosed in the first biopsy. Prostate needle biopsy Gleason score of 2 patients was reported as $3+3$. All patients had a tumor in only one core and all were clinical stage T1c. The final pathology was reported as high-grade prostatic intraepithelial neoplasia in patient 1, whereas nodular hyperplasia in patient 2. (Figure 1,

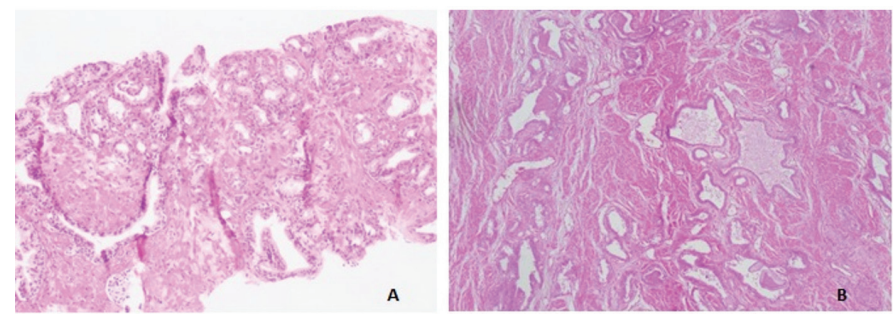

Figure 1. A- Crowded small glands of prostatic adenocarcinoma have amphophilic cytoplasm and enlarged nuclei with prominent nucleoli on needle core tissue. (Gleason score $3+3=6$ ). B- Invasive tumor has not been determined at radical parostatectomy of the same patient 
Figure 2) The mean prostate weight was $118 \mathrm{~g}$ (range, 110-126). The BCR was not detected in any patient.
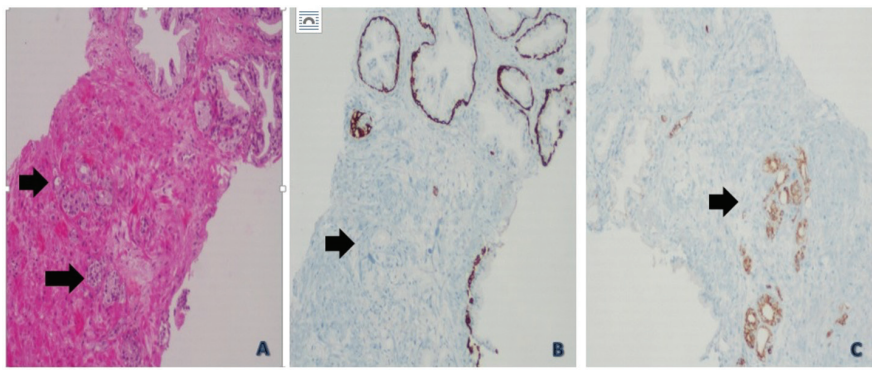

Figure 2. A- Small glands of adenocarcinoma (arrow), compared with benign glands (above) B- Basal cells of benign glands reactive with high-molecular weight cytokeratin (HMWK). Tumoral glands (arrow) do not express HMWK because basal cells are absent in invasive adenocarcinoma of the prostate. CNeoplastic prostatic epithelial cells show over-expression of AMACR (arrow)

Table 1. Characteristics of patients with pT0

\begin{tabular}{|l|l|l|}
\hline & Patient 1 & Patient 2 \\
\hline Age, years & 62 & 66 \\
\hline BMI, kg/m ${ }^{2}$ & 29.74 & 28.40 \\
\hline Abnormal DRE & No & No \\
\hline PSA, ng/mL & 24.62 & 3.93 \\
\hline Biopsy Gleason score & $3+3$ & $3+3$ \\
\hline Total number of cores, $\mathrm{n}$ & 10 & 12 \\
\hline Number of positive core, $\mathrm{n}$ & 1 & 1 \\
\hline Length of positive core, mm & 2 & 1 \\
\hline Percentage of cancer, $\%$ & 5 & 1 \\
\hline Preoperative stage & T1c & T1c \\
\hline D' Amico risk group & High & Low \\
\hline Specimen weight, g & 126 & 110 \\
\hline Final pathology result & HGPIN & Nodular hyperplasia \\
\hline Pathological N-stage & No & Nx \\
\hline Follow-up, months & 24 & 17 \\
\hline BCR & No & No \\
\hline Last visit PSA, ng/mL & 0.02 & $<0.0008$ \\
\hline BMrBody ms ince, & & \\
\hline
\end{tabular}

BMI: Body mass index, DRE: Digital rectal examination, PSA: Prostate-specific antigen, HGPIN: High-grade prostatic intraepithelial neoplasia, BCR: Biochemical recurrence

\section{Discussion}

The absence of residual tumor in RP specimens is called the "vanishing cancer phenomenon" (pT0) (3). This phenomenon, which is very rare and challenging for both clinicians and patients, is also important from a medicolegal perspective. The incidence of stage pT0 PCa ranges from $0.1 \%$ to $2.12 \%$ (10-26). The frequency of pTO PCa in our cohort was $0.4 \%$. This incidence is higher in patients diagnosed with incidental PCa during TURP or open prostatectomy performed to treat benign prostatic hyperplasia or patients who receive neoadjuvant hormonal therapy $(17,27)$. In these patients, a small tumor focus may be removed during a surgical procedure or obscured by hormonal therapy. The final true incidence rate is $0.1 \%-1.3 \%$ in patients diagnosed with PCa on prostate needle biopsy and who do not receive preoperative hormonal therapy $(10,12,13,15,16,18$ 20,23-25). The incidence and clinical outcomes of this group of patients are summarized in Table 2. Patients with tumors detected after the re-evaluation of RP specimen and prostate needle biopsy were not included in Table 2 . Thus, the final true incidence was determined.

Most patients with stage pT0 have been reported to have lower PSA levels, biopsy Gleason scores, and tumor burden. Park et al. (15) compared patients with and without stage pT0 and revealed that patients with pTO had significantly lower Gleason scores, a smaller number of positive cores, smaller tumor length, and larger prostate volume. Another study noted lower Gleason scores, a higher rate of lower-risk disease, and fewer positive cores in patients with pTO (11). A study that compared patients with stage pT0 with a control group revealed statistically significantly lower Gleason scores, tumor length in the biopsy, and the number of positive cores in the pTO group. Prostate volume was significantly larger (13). Schirrmacher et al. (21) compared patients with and without stage pT0 and reported that Gleason scores, tumor length, and the number of positive cores were significantly lower in patients with pT0. Moreira et al. (17) showed that the PSA level of patients with pTO was significantly lower than that of the control group. No comparative analysis was performed in our study. The mean PSA level of patients was $14.27 \mathrm{ng} / \mathrm{mL}$. Based on previous studies, a high mean PSA level can be associated with the fact that one of the two patients had a PSA of $24.62 \mathrm{ng} / \mathrm{dL}$. Two patients had a Gleason score of 6 . In addition, the tumor was detected in a single core in both. The mean tumor length in the positive core was $1.5 \mathrm{~mm}$.

The prognosis of patients with stage pTO is assumed to be satisfactory. Several studies have indicated no local recurrence or clinical progression in the follow-up period $(10,12-$ $16,20,23,24)$. This study observed no BCR or disease progression in any patients during the mean follow-up period of 21 months. In a population-based study conducted by Knipper et al. (11), cancer-specific death was observed in only 3 patients with pT0 during a 9 -year follow-up period. The cancer-specific survival rate in the 9 years was $99.5 \%$ in patients with pT0; however, it was 98.8\% in those without pT0. In a study including 62 patients with pT0, 7 (11\%) had disease relapse during the median of 10.9 years of follow-up (17). However, all these patients had received treatment before surgery. Compared with patients without pT0, those with pT0 were reported to have longer recurrence-free survival. Prayer-Galetti et al. (26) reported PSA progression in 
$3(12.5 \%)$ patients in their pT0 cohort study that included 24 patients. All patients who experienced PSA progression had undergone preoperative hormonal therapy. The absence of PSA progression in studies including patients who did not receive preoperative hormonal therapy indicates a favorable prognosis in these patients. However, caution must be exercised in the follow-up of these patients. Patients with pTO PCa should be followed up routinely. Thwaini et al. (28) reported that bone metastasis was detected during the follow-up of a patient with pT0 who did not receive hormonal therapy before the surgery.
Some researchers have investigated variables that can be used to predict stage pTO before RP. In the study by Park et al. (15), no multivariate logistic regression analysis could be performed, as the number of patients was low. However, they chose four criteria to predict pT0 disease: (1) Gleason score of $\leq 6$, (2) positive cores of $\leq 2$, (3) tumor size in biopsy of $\leq 2 \mathrm{~mm}$, and (4) prostate volume of $\geq 30 \mathrm{~cm}^{3}$. When these four criteria were combined, they calculated that the sensitivity of pT0 in predicting the disease was $88.8 \%$, specificity was $93.4 \%$, positive predictive value (PPV) was 12.7\%, and negative predictive value

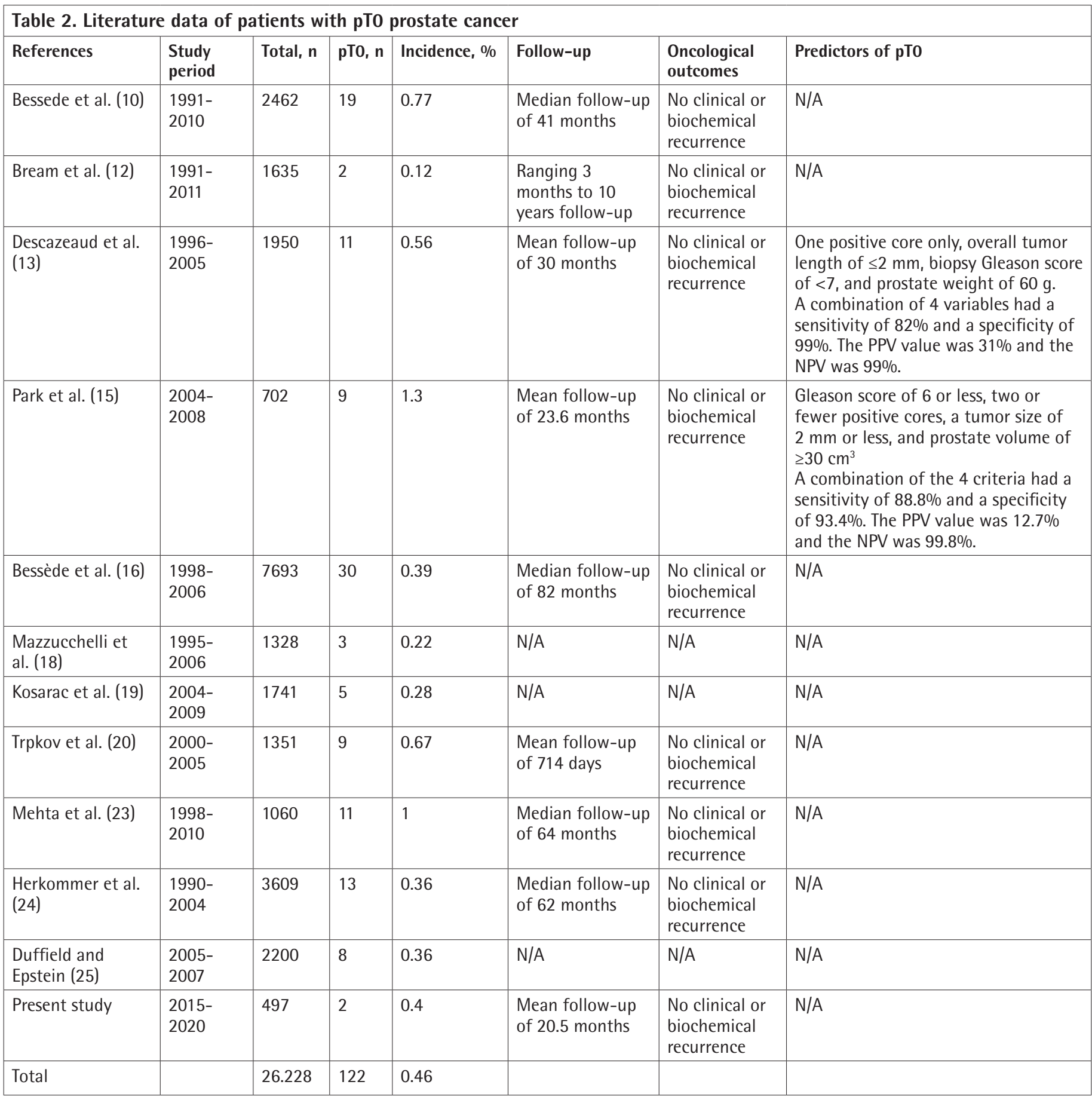


(NPV) was 99.8\%. Similarly, Descazeaud et al. (13) identified four criteria (i.e., single positive core, total tumor length in the biopsy of $\leq 2 \mathrm{~mm}$, Gleason score of $<7$, and prostate volume of $\geq 60 \mathrm{~g}$ ). The sensitivity of the combination of these criteria was $82 \%$, specificity was $99 \%$, PPV was $31 \%$, and NPV was $99 \%$. In a population-based study, the number of biopsy cores taken, a Gleason score of $\leq 6$, and the detection of tumors in a single core was shown as independent variables in multivariate logistic regression analysis to predict pTO disease (11). In a study of 20,222 patients, a multivariate analysis determined low PSA levels, low Gleason score, and preoperative hormonal therapy as independent variables in predicting pT0 disease (17). In this study, the Gleason score of two patients was 6 . The tumor was detected in a single core in both patients, and the tumor length was $<2 \mathrm{~mm}$. Our results are also consistent with the multivariate logistic regression analysis (11). Although the patient's PSA level is high, it should be considered that there is a risk of pTO.

Several reasons may be present for the absence of residual tumor in RP specimens following positive biopsy results. The possibility of a false-positive result on prostate needle biopsy should be considered first. Prostate needle biopsy tissue should be reexamined by a second pathologist, and the diagnosis of $\mathrm{PCa}$ should be confirmed. Another possibility is that the diagnosis of the RP specimen is a false negative. The specimen should be examined again for an overlooked residual tumor. If a tumor is still absent, the entire prostate tissue should be sampled. Further deeper re-cutting should be performed in the prostate tissue corresponding to the areas with positive biopsy results. Immunohistochemical staining should be used for minimal residual tumor and suspected foci. This step is critical to detect the tumor that has become a small focus as a result of preoperative hormonal treatment. As these steps were followed meticulously, tumors were detected in some patients with pTO. When the RP specimens of 8 patients with pTO were examined closely, it was determined that 6 of them had tumors (18). Similarly, in one study, no residual tumor was detected in 28 patients in the first examination, whereas the second examination revealed the presence of tumor in 10 patients (21). In a study by Duffield and Epstein (25), among 2,200 patients who underwent RP, 34 showed to have pT0 in the first pathological examination and a further examination revealed that 8 patients have pTO. In our study, both biopsy tissue and prostatectomy specimen results were meticulously reviewed and false positivity was noted in one patient biopsy result. Another possibility for the vanishing cancer phenomenon is the diagnostic treatment of the tumor. Tumor focus might have been removed during TURP and open prostatectomy. Moreover, a small tumor area might be completely regressed with hormonal therapy. However, this is unclear in prostate biopsy. Kommu introduced the curative biopsy theory and claimed that the malignancy focus might be completely removed by biopsy (29). Some researchers argue that necrosis may develop in tumor tissue due to vasospasm or hematoma and the tumor may disappear after a biopsy $(30,31)$. Evidence on this issue is insufficient. The last possible reason for the absence of a residual tumor is misnomenclature or confusion regarding the specimen. To eliminate this possibility, some researchers performed DNA analysis of the biopsy and surgical specimens $(3,10,20,22)$. DNA mismatch was detected in only 1 of the patients in these studies. No DNA analysis was performed in our study.

\section{Study Limitations}

Our study has some limitations. First, the study has a retrospective design. Furthermore, the number of patients in our study was small, and the follow-up period was relatively short. Owing to the small number of patients, no regression analysis could be performed for variables that could be used to predict pT0. Finally, the needle biopsy and RP pathology reports were verified by a second pathologist; however, no DNA analysis was performed.

\section{Conclusion}

No residual tumor after RP is extremely rare. Consensus about its clinical importance is unclear; however, patients should be routinely followed up. Patients with a Gleason score of 6 and tumors in a single core and length of $<2 \mathrm{~mm}$ in the biopsy should be informed about the risk of stage pTO, and active surveillance option should be explained.

\section{Ethics}

Ethics Committee Approval: The study was approved by Antalya Training and Research Hospital Ethics Committee (approval number: 2021-007).

Informed Consent: Retrospective study.

Peer-review: Externally peer-reviewed.

\section{Authorship Contributions}

Surgical and Medical Practices: E.I., K.Y., M.A., Ş.Y., Concept: K.K., M.T.Ö., M.A., Design: K.K., M.T.Ö., M.A., Data Collection or Processing: K.K., K.Y., O.A., Analysis or Interpretation: K.K., M.T.Ö., K.Y., O.A., Ş.Y., Literature Search: K.K., E.I., Writing: K.K., M.T.Ö., E.I., Ş.Y.

Conflict of Interest: No conflict of interest was declared by the authors.

Financial Disclosure: The authors declare that they have no relevant financial.

\section{References}

1. Siegel RL, Miller KD, Jemal A. Cancer statistics, 2018. CA Cancer J Clin 2018;68:7-30. 
2. DiGiuseppe JA, Sauvageot J, Epstein JI. Increasing incidence of minimal residual cancer in radical prostatectomy specimens. Am J Surg Pathol 1997;21:174-178.

3. Goldstein NS, Bégin LR, Grody WW, Novak JM, Qian J, Bostwick DG. Minimal or no cancer in radical prostatectomy specimens. Report of 13 cases of the "vanishing cancer phenomenon". Am J Surg Pathol 1995;19:1002-1009.

4. Kıran MM, Gümüşkaya B.'No Residual Tumor' Rate in Radical Cystectomy Specimens. J Urol Surg 2019;6:258-259.

5. Gross JL, Masterson TA, Cheng L, Johnstone PA. pT0 prostate cancer after radical prostatectomy. J Surg Oncol 2010;102:331-333.

6. Köllermann J, Feek U, Müller H, Kaulfuss U, Oehler U, Helpap B, Köllermann MW. Nondetected tumor (pT0) after prolonged, neoadjuvant treatment of localized prostatic carcinoma. Eur Urol 2000;38:714-720.

7. Boğa MS, Sönmez MG, Karamık K, Yılmaz K, Savaş $M$, Ateş $M$. The effect of peritoneal re-approximation on lymphocele formation in transperitoneal robot-assisted radical prostatectomy and extended pelvic lymphadenectomy. Turk J Urol 2020;46:460-467.

8. Montironi R, van der Kwast T, Boccon-Gibod L, Bono AV, Boccon-Gibod L. Handling and pathology reporting of radical prostatectomy specimens. Eur Urol 2003:44:626-636.

9. Karabulut YY. Interpreting a Radical Prostatectomy Report. J Urol Surg 2019;6:168-171.

10. Bessede T, Girodon E, Allory $Y$, Le Floch A, Leroy K, Salomon L. DNA comparison between operative and biopsy specimens to investigate stage pT0 after radical prostatectomy. World J Urol 2014;32:899-904.

11. Knipper $S$, Tilki $D$, Mazzone $E_{1}$ Mistretta FA, Palumbo C, Pecoraro $A_{1}$ Tian Z, Briganti A, Saad F, Graefen M, Karakiewicz PI. Contemporary clinicopathological characteristics of pTO prostate cancer at radical prostatectomy: A population-based study. Urol Oncol 2019;37:696-701.

12. Bream MJ, Dahmoush L, Brown JA. pTo Prostate Cancer: Predictive Clinicopathologic Features in an American Population. Curr Urol 2013;7:1418.

13. Descazeaud A, Zerbib M, Flam T, Vieillefond A, Debré B, Peyromaure M. Can pT0 stage of prostate cancer be predicted before radical prostatectomy? Eur Urol 2006;50:1248-1253.

14. Bostwick DG, Bostwick KC. 'Vanishing' prostate cancer in radical prostatectomy specimens: incidence and long-term follow-up in 38 cases. BJU Int 2004;94:57-58.

15. Park J, Jeong IG, Bang JK, Cho YM, Ro JY, Hong JH, Ahn H, Kim CS. Preoperative Clinical and Pathological Characteristics of pTO Prostate Cancer in Radical Prostatectomy. Korean J Urol 2010;51:386-390.

16. Bessède $T$, Soulié $M$, Mottet N, Rebillard X, Peyromaure M, Ravery V, Salomon $\mathrm{L}$; Cancerology Committee of the French Urological Association. Stage pT0 after radical prostatectomy with previous positive biopsy sets: a multicenter study. J Urol 2010;183:958-962.

17. Moreira DM, Gershman B, Rangel U, Boorjian SA, Thompson RH, Frank I, Tollefson MK, Gettman MT, Karnes RJ. Evaluation of pT0 prostate cancer in patients undergoing radical prostatectomy. BJU Int 2016;118:379-383.
18. Mazzucchelli R, Barbisan F, Tagliabracci A, Lopez-Beltran A, Cheng L, Scarpelli M, Montironi R. Search for residual prostate cancer on pT0 radical prostatectomy after positive biopsy. Virchows Arch 2007;450:371-378.

19. Kosarac O, Zhai OJ, Shen S, Takei H, Ro JY, Ayala AG. Minimal or no residual prostatic adenocarcinoma on radical prostatectomy: a 5-year experience with "vanishing carcinoma phenomenon". Arch Pathol Lab Med 2011;135:1466-1470.

20. Trpkov K, Gao Y, Hay R, Yimaz A. No residual cancer on radical prostatectomy after positive 10-core biopsy: incidence, biopsy findings, and DNA specimen identity analysis. Arch Pathol Lab Med 2006;130:811-816.

21. Schirrmacher $S$, Kallidonis $P$, Horn LC, Nenning H, Rassler J, Rai B, Do $M$, Liatsikos E, Stolzenburg JU. Stage pT0 after radical prostatectomy: a diagnostic dilemma. World J Urol 2015;33:1291-1296.

22. Cao D, Hafez M, Berg K, Murphy K, Epstein Jl. Little or no residual prostate cancer at radical prostatectomy: vanishing cancer or switched specimen?: a microsatellite analysis of specimen identity. Am J Surg Pathol 2005;29:467473.

23. Mehta V, Mehrotra S, Flanigan RC, Wojcik EM, Venkataraman G. Vanishing prostate cancer on radical prostatectomy (RP) in the PSA era: incidence and follow-up data from a cohort of 1,060 patients between 1998 and 2010. Virchows Arch 2011;459:115-116.

24. Herkommer $K$, Kuefer $R$, Gschwend JE, Hautmann RE, Volkmer BG. Pathological T0 prostate cancer without neoadjuvant therapy: clinical presentation and follow-up. Eur Urol 2004;45:36-41.

25. Duffield AS, Epstein JI. Detection of cancer in radical prostatectomy specimens with no residual carcinoma in the initial review of slides. Am J Surg Pathol 2009;33:120-125.

26. Prayer-Galetti T, Gardiman M, Sacco E, Fracalanza S, Betto G, Pinto F. Finding of no tumor (pT0) in patients undergoing radical retropubic prostatectomy for clinically localized prostate cancer. Anal Quant Cytol Histol 2007;29:7986.

27. Noguchi M, Noda S, Nakashima 0 , Kojiro M. No residual tumor in a radical prostatectomy specimen after neoadjuvant hormonal therapy for localized prostate cancer. Oncol Rep 2002;9:1075-1080.

28. Thwaini A, Anjum F, Kalubac J, Shergill IS, Lewi HJ. 'Vanishing' prostate cancer in radical prostatectomy specimens: incidence and long-term follow-up in 38 cases. BJU Int 2004;94:1145-1146.

29. Kommu S. A model to explain the 'vanishing' prostate -- the curative biopsy theory. BJU Int 2004;94:939-940.

30. Chan NN. A vanishing pituitary mass. Postgrad Med J 2000;76:720, 729-31.

31. Yamashita $Y$, Kumabe T, Shimizu H, Ezura M, Tominaga T. Spontaneous regression of a primary cerebral tumor following vasospasm caused by subarachnoid hemorrhage due to rupture of an intracranial aneurysm-case report. Neurol Med Chir (Tokyo) 2004:44:187-190. 